\title{
Enhanced aquifer thermal energy storage for cooling and heating of Shinshu University building using a nested well system
}

\author{
A. Tomigashi \& K. Fujinawa \\ Department of Civil Engineering, Shinshu University, Japan
}

\begin{abstract}
An enhanced aquifer thermal energy storage (ATES) is proposed in this paper in order to provide cooling and heating energy from groundwater to an airconditioning system of a building at Shinshu University. By adopting the enhanced ATES, a nested well system composed of withdrawal and injection wells is under construction in which an upper unconfined aquifer is used to withdraw, inject and store cooling water, and an underlying confined aquifer is used for heating water. A variety of field tests including all-core boring, electrical logging, thermal logging, pumping tests and thermal and salt-water tracer tests has been performed to identify hydrogeologic and thermal properties of the aquifer. Numerical simulations were then conducted by using SWATER (Subsurface Water and Thermal Energy Resources), which is a program for simulating three-dimensional water flow and heat transport in aquifer systems. The numerical results showed that the enhanced ATES is superior to the conventional ATES in terms of recovered thermal energy.
\end{abstract}

Keywords: enhanced aquifer thermal energy storage, nested well system, field tests, control of groundwater flow and heat transport, numerical simulation.

\section{Introduction}

Underground space provides a large isolated storage volume of water for thermal energy. Underground Thermal Energy Storage (UTES) technologies use the capacity of this volume to store thermal energy for seasonal application. Among UTES, Aquifer Thermal Energy Storage (ATES) and Borehole Thermal Energy Storage (BTES) are widely used techniques. An ATES system uses groundwater as the medium of heat transfer between an external source and the aquifer while 
a BTES system delivers or extracts heat and cold from the underground by means of circulation of a fluid in a U-tube. Wherever groundwater is abundant, ATES can provide an attractive sustainable energy for cooling and heating various facilities. For example, the Matsumoto basin in Nagano Pref. stores about 10 billion $\mathrm{m}^{3}$ of groundwater. The delivery or extraction of thermal energy by $5^{\circ} \mathrm{C}$ from the groundwater can cool and heat spaces with the energy of $13 \mathrm{GWt}$.

In a UTES system, the stored cold is pumped back and the waste heat from the cooling process is stored in a warm zone, and vice versa. However, the stored heat or cold may be transported by flowing groundwater and dissipate due to dispersion if groundwater flow and heat transport is not properly controlled. The basic idea of an enhanced ATES is to establish a withdrawal/recharge well system along a groundwater flow line and to control groundwater flow by adjusting the hydraulic gradient by means of pumping and injection. This system enables maximized heat and cold recovery by optimizing the withdrawal and injection rates at the nested wells. Table 1 summarises the advantages and the disadvantages of the conventional and the enhanced ATES together with BTES. Although special care must be taken with respect to land subsidence and clogging of sediment pores, the enhanced ATES has a great advantage over the others in terms of energy output per borehole, recovery of stored thermal energy and safety against thermal and chemical pollution of groundwater. Besides all of these advantages, the enhanced ATES further assures that the efficiency of the system can be gradually improved as the system operation is continued.

In the fiscal year of 2010, a pilot project of the enhanced ATES was initiated with the financial support of the Japanese New Energy and Industrial Technology Development Organization at the Nagano campus of Shinshu University. This paper shows how the system is designed and how the efficiency of ATES is improved by using numerical simulation along with input data acquired by field tests.

Table 1: Features of various UTES.

\begin{tabular}{l|c|c|c|l}
\hline \multicolumn{1}{c|}{ Evaluation } & (B) & (A1) & (A2) & \\
\hline Energy output per borehole & $\times$ & $\boldsymbol{\Delta}$ & $\mathbf{O}$ & \\
\hline Recovery of stored thermal energy & $\times$ & $\boldsymbol{\Delta}$ & $\mathbf{O}$ & \\
\hline Possible Impact on geo-environment & $\boldsymbol{O}$ & $\times$ & $\times$ & (A1),(A2): land subsidence \\
\hline Safety against thermal pollution & $\times$ & $\times$ & $\boldsymbol{O}$ & (B),(A1): uncontrolled thermal plume \\
\hline Safety against groundwater pollution & $\times$ & $\boldsymbol{O}$ & $\boldsymbol{O}$ & (B): leakage of antifreeze fluid \\
\hline Actual performance in Japan & $\boldsymbol{O}$ & $\boldsymbol{\Delta}$ & - & (A2): emerging technology \\
\hline System maintenance & $\boldsymbol{O}$ & $\boldsymbol{\Delta}$ & $\boldsymbol{\Delta}$ & (A1),(A2): clogging of sediment pores \\
\hline
\end{tabular}

(B) BTES, (A1) conventional ATES, (A2) enhanced ATES: Oexcellent, $\boldsymbol{\Delta}$ medium, $\times$ poor

\section{Field investigation of hydrogeology and groundwater}

The Nagano Campus of Shinshu University is located in the central part of the Nagano basin that is formed by the sediments of the Sai River and the Sunobana River as shown in Figure 1. The temperature of the area rises beyond $30^{\circ} \mathrm{C}$ more than 50 days a year and goes below zero 100 days a year with an average 
accumulated snowfall of $170 \mathrm{~cm}$. Thus, cooling during summer and heating during winter are a common practice in this area. This means that there is a great potential to shift energy for cooling and heating from fossil fuels to a renewable thermal energy produced by ATES. The objective of the pilot project that started at the Shinshu University campus is to demonstrate the usefulness of a new system of the enhanced ATES.

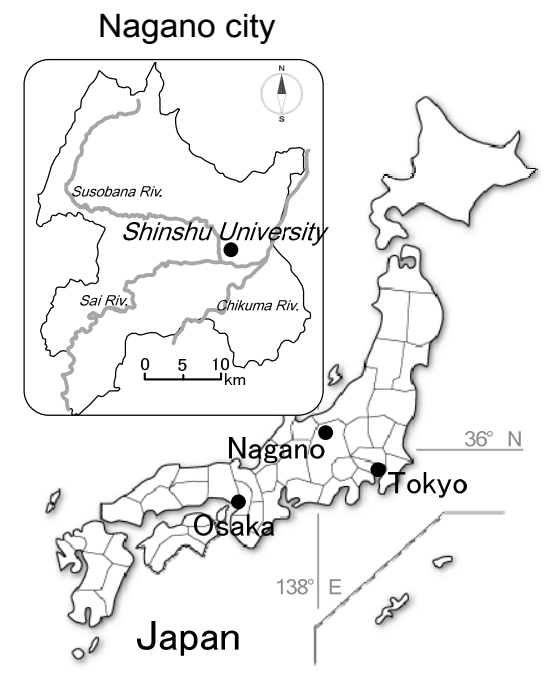

Figure 1: Location of the pilot project site at Shinshu University

The geologic structure of the site was investigated by sampling a boring core from a $75 \mathrm{~m}$ deep borehole and performing an electrical logging using an $80 \mathrm{~m}$ deep borehole. Figure 2 illustrates the results which show that under the surficial deposit of clay, a layer $8 \mathrm{~m}$ thick, lies an unconfined aquifer $32 \mathrm{~m}$ in height, which is underlain by a clay layer $3 \mathrm{~m}$ thick. A confined aquifer $21 \mathrm{~m}$ in height is further deposited below the clay layer. Underneath this is another clay layer $1 \mathrm{~m}$ thick below which lies a third aquifer. Each aquifer, composed of sand and gravel, is named aquifer 1, 2, and 3 from the top to the bottom.

A multi-screened well was installed in borehole B while three observation wells for each aquifer were constructed $3.8 \mathrm{~m}$ apart from borehole B. The observation wells were named A1 for aquifer 1, A2 for aquifer 2 and A3 for Aquifer 3. Sensors for measuring pore pressure, temperature and electrical conductivity were installed at each observation well. Monitored hydraulic heads show a tendency that the head in aquifer 1 is $20 \mathrm{~cm}$ higher than that of aquifer 2 and $50 \mathrm{~cm}$ higher than that of aquifer 3.

The direction and the velocity of groundwater flow in the aquifers were investigated at each observation well by means of multi-thermosensor equipment. The observed result indicates that the directions and the velocities of the flow in aquifers $1 \sim 3$ are SSE with $3.3 \times 10^{-3} \mathrm{~cm} / \mathrm{sec}$, SE with $6.4 \times 10^{-3} \mathrm{~cm} / \mathrm{sec}$ and SSW with $0.42 \times 10^{-3} \mathrm{~cm} / \mathrm{sec}$, respectively. 


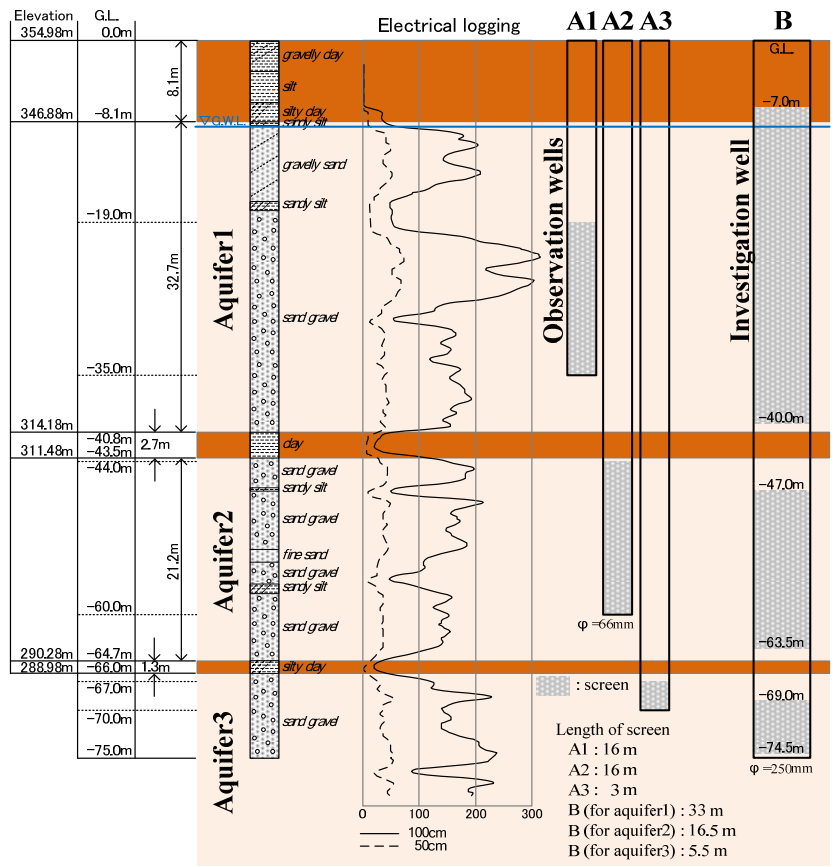

Figure 2: Lithology and the result of electrical logging for the pilot project site.

Pumping tests for each aquifer were performed using well $\mathrm{B}$ as a pumping well and wells A1 A3 as observation wells. The evaluated hydraulic conductivities of aquifers 1,2 and 3 are $2.28 \times 10^{-2} \mathrm{~cm} / \mathrm{sec}, 1.81 \times 10^{-2} \mathrm{~cm} / \mathrm{sec}$, $2.07 \times 10^{-1} \mathrm{~cm} / \mathrm{sec}$, respectively. A thermal logging was also conducted to investigate a vertical profile of groundwater temperature. It was revealed that the temperature distribution was almost constant and was around $14^{\circ} \mathrm{C}$ throughout each of the layers, except in aquifer 2 where the temperature was higher by $0.3^{\circ} \mathrm{C}$.

Clogging of sediment pores during injection of pumped groundwater into aquifers is a major obstacle to ATES. The main causes of the clogging are attributed to chemical precipitation, air-bubble formation and transport of fine soil particles through sediment pores of aquifers. Thus, chemical composition of the groundwater was investigated and the results are shown in Table 2. The observed groundwater quality suggests that the pilot project should take care of the clogging by introducing a water quality control system using ion exchange resin and de-aeration.

Subsurface, heat is transferred by heat conduction together with forced and natural convection of groundwater flow while dissipating due to dispersion. In order to investigate the response of the groundwater system against the stress of alien substances and that of heat, and eventually to evaluate dispersivity, thermal conductivity and heat capacity, two types of tracer tests using salt water and cold water were performed. Figure 3 shows a schematic diagram of the tracer tests conducted for aquifer 2. Salt water or cold water in a storage tank was injected 
into borehole B, and electrical conductance (EC), temperature (T), and hydraulic head $(\mathrm{H})$ were monitored at four sensor locations as illustrated in Figure 3. Sensor S1 and S2 were installed in the observation well A2 to measure EC, T and $\mathrm{H}$. Hydraulic head was monitored at borehole $\mathrm{B}$ while $\mathrm{EC}$ and $\mathrm{T}$ were monitored in the storage tank as well.

Table 2: Quality of groundwater in each aquifer

\begin{tabular}{|c|c|c|c|}
\hline Analysis item & Aquifer1 & Aquifer2 & Aquifer3 \\
\hline $\mathrm{Fe}$ & $0.05 \mathrm{mg} / \mathrm{L}$ & $1.1 \mathrm{mg} / \mathrm{L}$ & $0.65 \mathrm{mg} / \mathrm{L}$ \\
\hline Soluble Fe & $0.06 \mathrm{mg} / \mathrm{L}$ & $0.02 \mathrm{mg} / \mathrm{L}$ & $0.03 \mathrm{mg} / \mathrm{L}$ \\
\hline $\mathrm{Mn}$ & $0.7 \mathrm{mg} / \mathrm{L}$ & $0.82 \quad \mathrm{mg} / \mathrm{L}$ & $1.2 \mathrm{mg} / \mathrm{L}$ \\
\hline $\mathrm{Ca}$ & $20 \mathrm{mg} / \mathrm{L}$ & $23 \mathrm{mg} / \mathrm{L}$ & $21 \mathrm{mg} / \mathrm{L}$ \\
\hline $\mathrm{Mg}$ & $6.7 \mathrm{mg} / \mathrm{L}$ & $7.7 \mathrm{mg} / \mathrm{L}$ & $8.8 \mathrm{mg} / \mathrm{L}$ \\
\hline
\end{tabular}

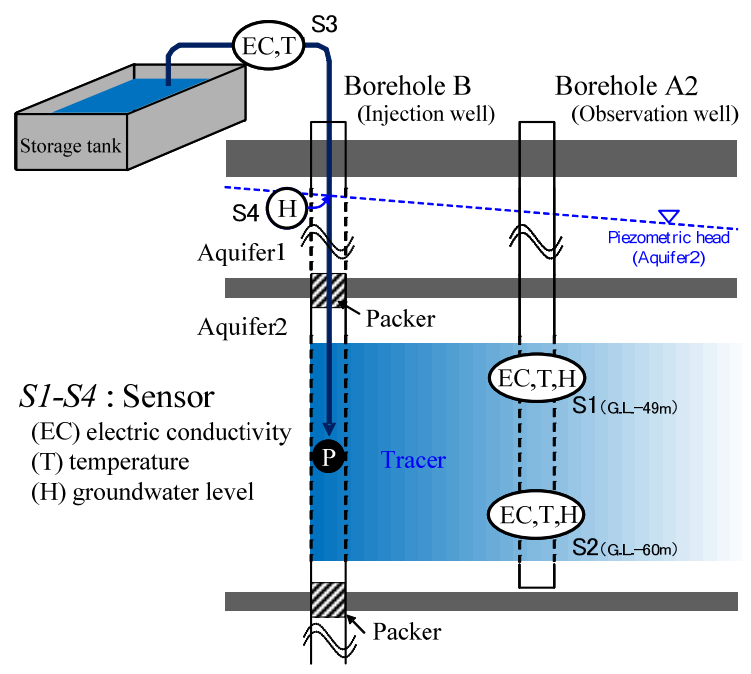

Figure 3: A schematic diagram of tracer tests for aquifer 2.

The results of the tracer tests, where the difference of hydraulic head in borehole B from A2 was $40 \mathrm{~cm}$, are shown in terms of relative concentration and temperature in Figure 4. The EC of the salt water injected was 2,425 mS/m and the peak concentrations at the depth of $49 \mathrm{~m}$ and $60 \mathrm{~m}$ below ground level in borehole A2 were $389.4 \mathrm{mS} / \mathrm{m}$ and $503.7 \mathrm{mS} / \mathrm{m}$, respectively. The peak concentrations at the depth of $49 \mathrm{~m}$ and $60 \mathrm{~m}$ emerged after $66 \mathrm{~min}$ and $51 \mathrm{~min}$ from the start of salt water injection, respectively.

The injection of cold water ranging from $2.0 \sim 3.8^{\circ} \mathrm{C}$ into aquifer $2\left(14.2^{\circ} \mathrm{C}\right)$ lasted $480 \mathrm{~min}$. The temperature at the depth of $49 \mathrm{~m}$ below ground level in borehole A2 went down by $0.6^{\circ} \mathrm{C} 662 \mathrm{~min}$ after the start of the cold water injection. It is interesting to note that there was no change in the temperature at the depth of $60 \mathrm{~m}$ in borehole A2. 
Based on the results of these tracer tests, parameters for numerical simulation such as longitudinal and transverse dispersivity, thermal conductivity and heat capacity can be evaluated by solving inverse problems. The procedure of the inverse problems and results will be discussed elsewhere.
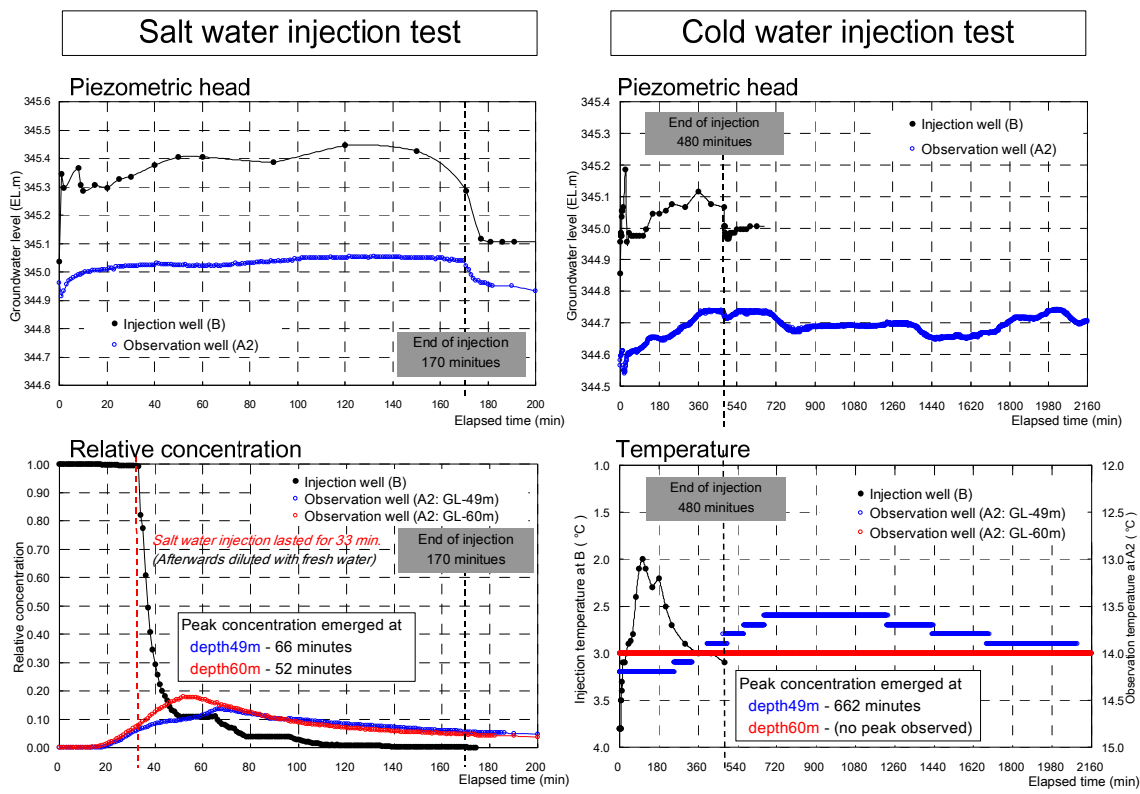

Figure 4: Results of tracer tests (left: salt water, right: cold water).

\section{System design of the enhanced ATES}

In accordance with the field investigations mentioned in the previous section, an enhanced ATES system was designed to supply cooling and heating groundwater to an air-conditioning system for three lecture rooms of a Shinshu University building. Figure 5 shows a plan view of the campus and Figure 6 illustrates the nested wells for pumping and injecting groundwater. Wells B, C1, C2, D1 and D2 are used for withdrawal or injection for controlling groundwater flow so that stored cold and heat can be recovered as much as possible. Cold water is designed to be stored in aquifer 1 and warm water in aquifer 2 . Since natural groundwater is supposed to flow from NW to $\mathrm{SE}, \mathrm{C} 1$ and $\mathrm{C} 2$ are planned to be used for injection, and D1 and D2 for recovery, so that hydraulic gradient is reduced accordingly. An operational condition of air conditioning for the pilot project is shown in Table 3. The optimized control of groundwater flow can be achieved with the aid of numerical simulation. 


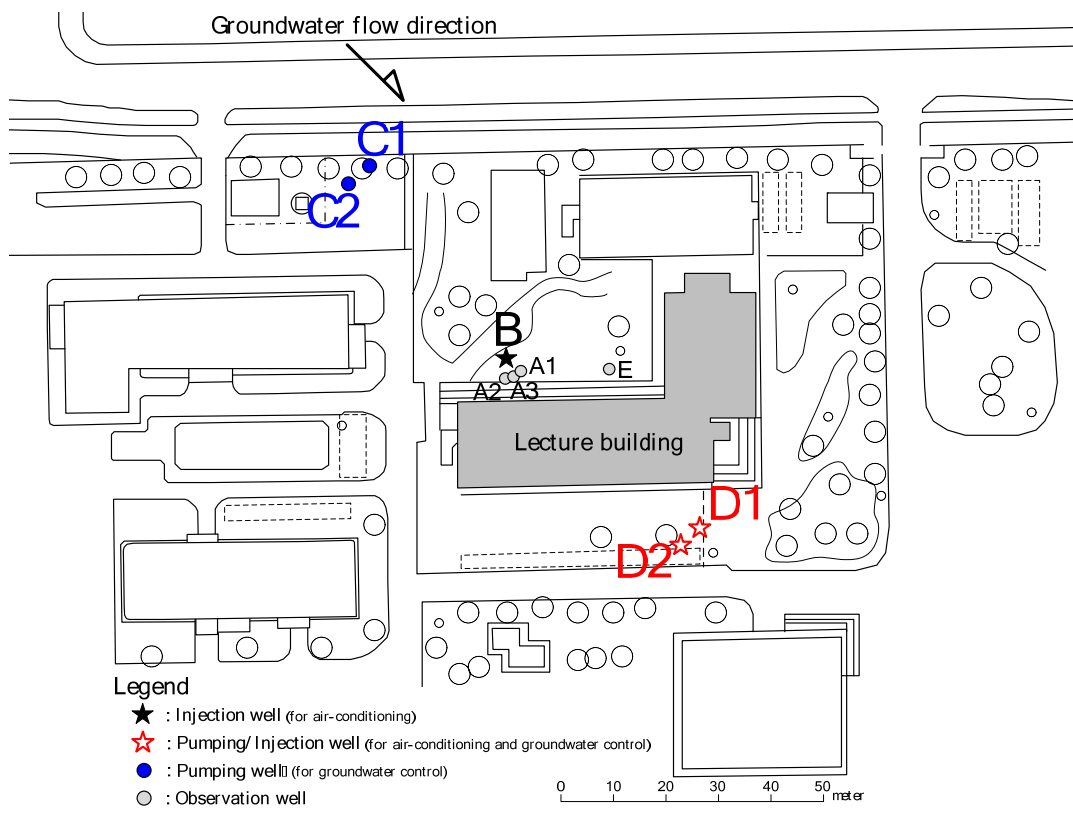

Figure 5: An enhanced ATES system for a Shinshu University building.

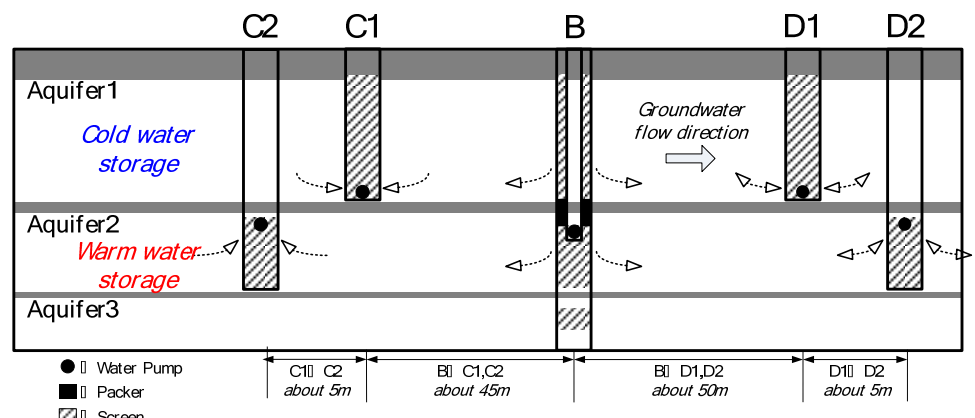

Figure 6: Nested wells for pumping and injecting groundwater.

Table 3: Operation for air-conditioning.

\begin{tabular}{|c|c|c|c|c|c|}
\hline \multirow{2}{*}{$\begin{array}{c}\text { Operation } \\
\text { mode }\end{array}$} & \multicolumn{2}{|c|}{ Period } & \multicolumn{2}{|c|}{ Pumping / Injection rate } & \multirow{2}{*}{$\begin{array}{c}\text { Injection } \\
\text { water temperature }\end{array}$} \\
\hline & date & number of days & (L/day) & $(\mathrm{L} / \mathrm{min})$ & \\
\hline Heating & $11 / 1-4 / 30$ & 180 & 72,000 & 50.0 & $5^{\circ} \mathrm{C}$ const. \\
\hline Suspend & $5 / 1-5 / 31$ & 31 & - & - & - \\
\hline Cooling & $6 / 1-9 / 30$ & 122 & 72,000 & 50.0 & $25^{\circ} \mathrm{C}$ const. \\
\hline Suspend & $10 / 1-10 / 31$ & 31 & - & - & - \\
\hline
\end{tabular}




\section{Numerical simulation of the enhanced ATES}

In order to facilitate an optimal design of the enhanced ATES, a numerical simulation program, SWATER3di (Subsurface Water and Thermal Energy Resources in three dimension), was developed. SWATER is based on a program, SIFEC (Saltwater Intrusion by Finite Element and Characteristics: Fujinawa et al [1]), for variable-density, saturated-unsaturated, coupled flow and solute transport except that SWATER is a three dimensional version using triangular prism elements and modified to simulate heat transport instead of mass transport. The program was verified by comparing its accuracy with experimental results and other numerical results conducted by Fujinawa [2]. The governing equations and auxiliary formulas adopted in SWATER are given in the appendix.

Figure 7 shows the finite element mesh used to simulate groundwater flow and heat transport at the pilot project site. The number of nodes is 12,852 , and the number of elements 23,712 . The dimension of the model is $400 \mathrm{~m}$ long, $100 \mathrm{~m}$ wide and $64.7 \mathrm{~m}$ deep.

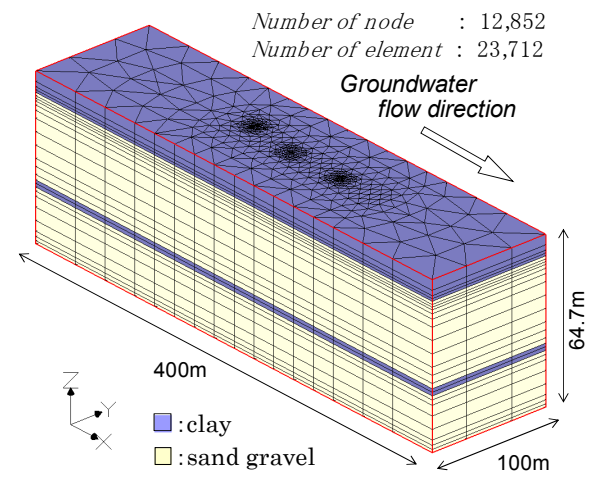

Figure 7: 3D finite element mesh for the pilot project site.

The robust evaluation of all the hydrogeologic and thermal parameters is now under way. For an interim simulation, these parameters are temporally fixed using data from the field investigations and from values reported in the literature for the fields similar to the pilot project site. Table 4 shows the parameters used in the numerical simulation. These parameters are noted in the appendix along with governing equations describing saturated-unsaturated flow and heat transport in an aquifer system.

The boundary conditions for subsurface water flow were assigned so that the hydraulic gradient of natural groundwater flow is equal to $1 / 100$. The top, bottom and side boundaries were treated as an impervious boundary. As for initial conditions, total head was interpolated in accordance with the hydraulic gradient with that of aquifer $120 \mathrm{~cm}$ higher than that of aquifer 2 .

A constant temperature of $14.0^{\circ} \mathrm{C}$ was assigned at the upstream boundary, while the top, bottom, side and downstream boundaries were treated as an insulated boundary. Initial groundwater temperature was assumed to be $14^{\circ} \mathrm{C}$ throughout the analytical domain. 
The rate of groundwater withdrawal for heating and cooling was $72 \mathrm{~m}^{3} /$ day. And, the same amount of water pumped from an aquifer was injected into another aquifer. It was assumed that thermal energy is produced so that cooling makes pumped water $25^{\circ} \mathrm{C}$ and heating makes it $5^{\circ} \mathrm{C}$. The water discharged after the use of air-conditioning is in turn injected into the aquifer different from the pumped one with the relevant temperature.

Table 4: Parameters used for numerical analysis.

\begin{tabular}{l|c|c|c}
\hline \multicolumn{5}{l}{ Saturated hydraulic conductivity at a reference temperature of $4^{\circ} \mathrm{C}$} \\
\hline Clay & $\mathrm{K}_{\mathrm{r}}$ & 0.00036 & $\mathrm{~m} / \mathrm{hr}$ \\
\hline Sand gravel (Aquifer 1) & $\mathrm{K}_{\mathrm{r}}$ & 0.821 & $\mathrm{~m} / \mathrm{hr}$ \\
\hline Sand gravel (Aquifer 2) & $\mathrm{K}_{\mathrm{r}}$ & 0.652 & $\mathrm{~m} / \mathrm{hr}$ \\
\hline Porosity & $\varepsilon$ & 0.200 & - \\
\hline Saturated water content & $\theta_{\mathrm{s}}$ & 0.200 & - \\
\hline Residual water content & $\theta_{\mathrm{r}}$ & 0.100 & - \\
\hline Parameter of van Genuchten eq. & \multicolumn{5}{l}{} \\
\hline$\alpha$ & & 5.270 & $/ \mathrm{m}$ \\
\hline$\beta$ & $\alpha_{\mathrm{L}}$ & 1.0 & $\mathrm{~m}$ \\
\hline Longitudinal dispersivity & $\alpha_{\mathrm{T}}$ & 0.1 & $\mathrm{~m}$ \\
\hline Transverse dispersivity & $(\rho \mathrm{C})_{\mathrm{s}}$ & 528.00 & $\mathrm{~J} / \mathrm{m} 3 \mathrm{~K}$ \\
\hline Volumetric heat capacity of & $(\rho \mathrm{C})_{\mathrm{w}}$ & 1160.00 & $\mathrm{~J} / \mathrm{m} 3 \mathrm{~K}$ \\
\hline Solid phase & $(\rho \mathrm{C})_{\mathrm{a}}$ & 0.336 & $\mathrm{~J} / \mathrm{m} 3 \mathrm{~K}$ \\
\hline Water phase & $\lambda_{\mathrm{s}}$ & 0.909 & $\mathrm{~W} / \mathrm{mK}$ \\
\hline Air phase & $\lambda_{\mathrm{w}}$ & 0.594 & $\mathrm{~W} / \mathrm{mK}$ \\
\hline Heat conductivity of & $\lambda_{\mathrm{a}}$ & 0.024 & $\mathrm{~W} / \mathrm{mK}$ \\
\hline Solid phase
\end{tabular}

Two types of simulation for the conventional and the enhanced ATES were performed. The operational condition for both types is the same as shown in Table 3. However, the enhanced ATES withdraws $144 \mathrm{~m}^{3} /$ day from well $\mathrm{C} 1$ or C2 and injects the same amount of water into well D2 or D1 to control groundwater flow. The temperature of the injected water is made equal to the average temperature of the pumped groundwater.

Figure 8 shows the simulated results for the conventional and the enhanced ATES. The profiles of groundwater temperature were illustrated for one-cyclic year. The aquitard separating aquifer 1 from aquifer 2 plays an important role in preventing a mixture of cold and warm water in the aquifer system. It is confirmed from the figure that the central temperature in the cold plume for the enhanced ATES is lower than that for the conventional ATES, and that in the warm plume for the enhanced ATES, is higher than that for the conventional ATES. In terms of the recovery of stored thermal energy, the enhanced ATES was superior to the conventional ATES.

To show the efficiency of thermal energy storage, the temporal change in the average temperature of pumped groundwater is illustrated in Figure 9. During the cooling season, colder groundwater is recovered when the enhanced ATES is used, compared with the conventional ATES. Although chilled groundwater is recovered during the initial stage of the heating season, warmer groundwater, compared with the conventional ATES, is recovered as a whole when the enhanced ATES is used. The efficiency of the enhanced ATES can be optimized 


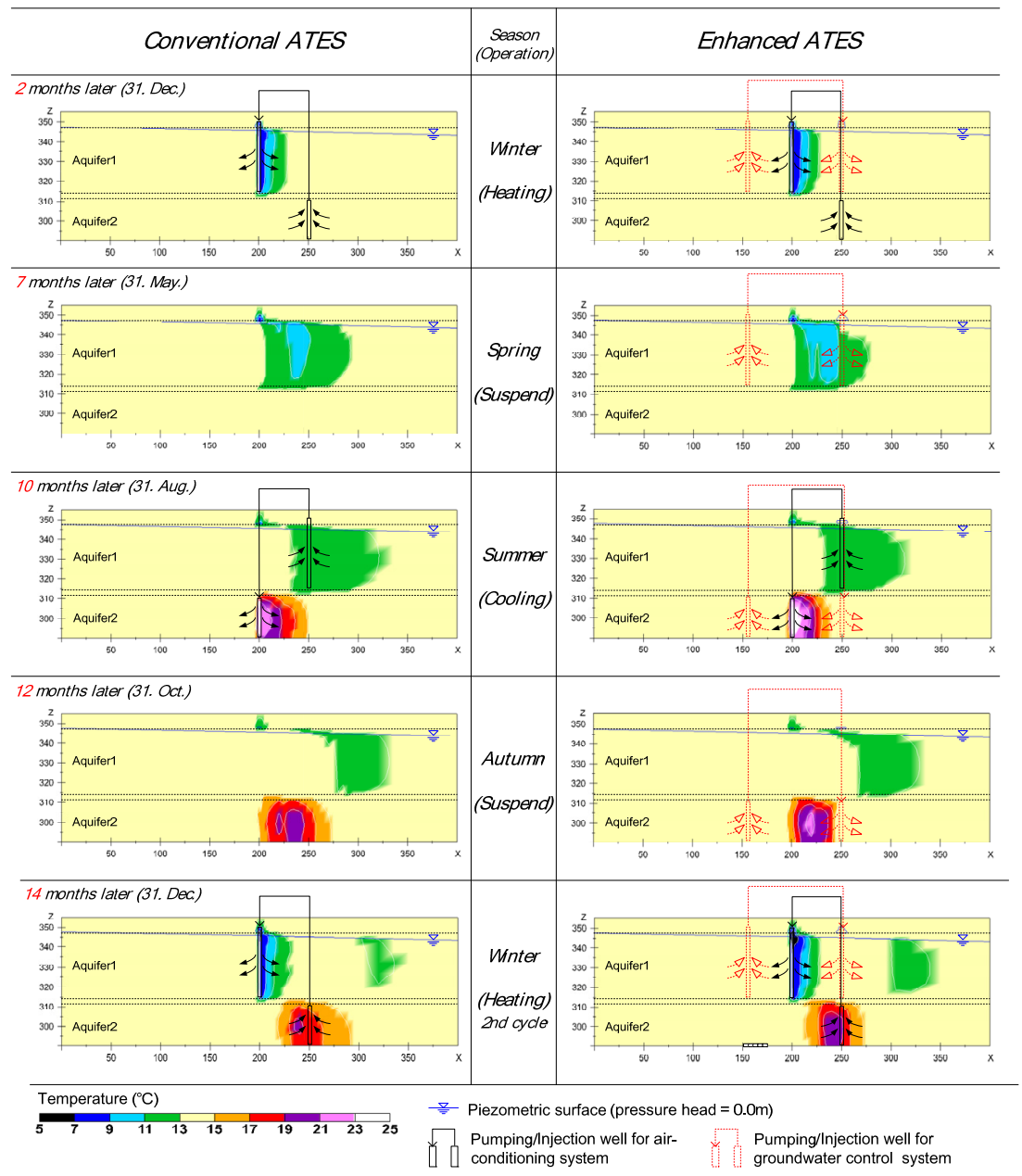

Figure 8: Simulated results of groundwater temperature profile.

by using the nested well system and adjusting the rate and the period of pumping and injection.

\section{Conclusion}

As a new technology for utilizing renewable energy with a great potential for cooling and heating buildings and houses and for taking over fossil fuels, an enhanced aquifer thermal energy storage (ATES) is proposed in this paper. The basic concept of the enhanced ATES is based on the modification of the conventional ATES so that the possible transport of cold and heat stored in aquifer systems be controlled to maximize its recovery. To demonstrate the efficiency of the technology, a pilot project was launched at the campus of 


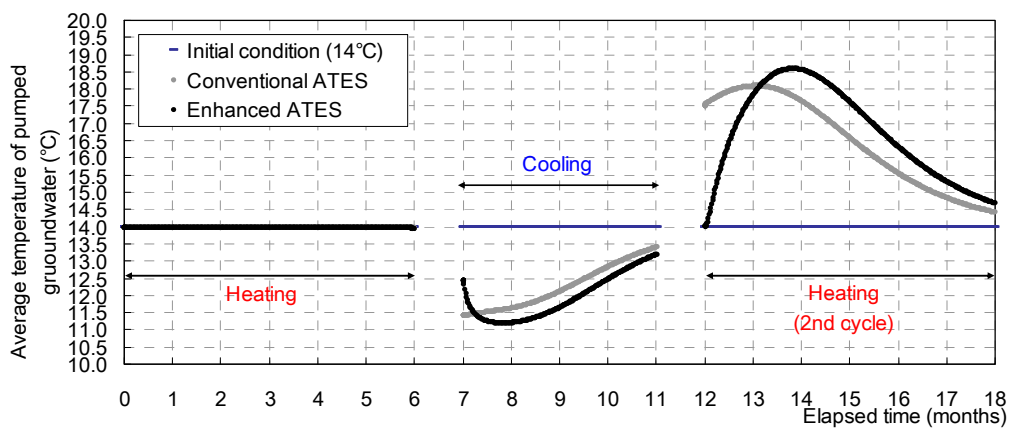

Figure 9: Average temperature of pumped groundwater.

Shinshu University. Hydrogeologic and thermal properties of the site were investigated by conducting various field tests including all-core boring, electrical logging, thermal logging, pumping tests and thermal and salt-water tracer tests. It was revealed that the aquitard separating unconfined aquifer from confined aquifer can play an important role in preventing a mixture of cold and warm water in the aquifer system.

A nested well system composed of withdrawal, injection and monitor wells was then designed. Based on the data acquired by the field tests, numerical simulations were performed to compare the efficiency of the enhanced ATES with the conventional ATES. The numerical results showed that the enhanced ATES is superior to the conventional ATES in terms of recovery of the stored thermal energy. The use of numerical simulation tools such as SWATER makes it possible to design an optimal system depending on field conditions and characteristics of facilities to be air-conditioned.

\section{Acknowledgement}

This research has been financially supported by the Japanese New Energy and Industrial Technology Development Organization.

\section{Appendix}

The governing equation for flow of water in saturated-unsaturated zone with variable-density fluid is given by

$$
\nabla \bullet\left\{\frac{\mu_{r} K_{r}}{\mu}\left(\nabla h_{r}+\frac{\rho}{\rho_{r}} \nabla z\right)\right\}-\sum_{i=1}^{n_{q}} Q_{i} \delta_{i}=\rho\left(S_{e} S_{s} \frac{\partial h_{r}}{\partial t}+C_{s} \frac{\partial h_{r}}{\partial t}\right)+\varepsilon S_{e} \frac{\partial \rho}{\partial t}
$$

where $\rho$ and $\rho_{r}$ are the density of water; $\mu$ and $\mu_{r}$ are the dynamic viscosity of freshwater; $S_{e}$ is the fractional effective water saturation; $S_{s}$ is the specific storage; $h_{r}$ is the pressure head in terms of water of a reference temperature; $C_{s}\left(=\varepsilon \partial S_{e} / \partial h_{r}\right)$ is the soil water capacity; $\varepsilon$ is the fractional porosity; $K_{r}$ is the hydraulic conductivity in terms of water of a reference temperature; $Q_{i}$ is the 
withdrawal rate of a pumping well $i ; \delta_{i}$ is the Dirac delta function for the pumping or injection well; $z$ is the upward vertical coordinate.

For unsaturated porous media, van Genuchten [3] provided functional relations for the parameters $S_{e}$ and $K_{r}$ in Equation (1) as follows:

$$
\begin{gathered}
S_{e}=\frac{\theta-\theta_{r}}{\theta_{s}-\theta_{r}}=\frac{1}{\left(1+\left|\alpha h_{f}\right|^{\beta}\right)^{r}}, \quad\left(\gamma=1-\frac{1}{\beta}\right) \\
K_{r}=K_{r s} S_{e}^{1 / 2}\left\{1-\left(1-S_{e}^{1 / \gamma}\right)^{\gamma}\right\}^{2}
\end{gathered}
$$

where $\theta, \theta_{s}$ and $\theta_{r}$ are the volumetric water content (VWC), the saturated $\mathrm{VWC}$, and the residual VWC, respectively; $\alpha$ and $\beta$ are the characteristic constants of soil to be evaluated from experiments; $K_{r s}$ is the saturated hydraulic conductivity in terms of a reference temperature.

The governing equation for heat transport in the saturated-unsaturated zone is given by

$$
\nabla \bullet(\lambda \nabla T)-\theta(\rho C)_{w} \nabla \bullet(\mathbf{v} T)=(\rho C) \frac{\partial T}{\partial t}
$$

where $\mathrm{T}$ is temperature; $(\rho C)_{w}$ is the volumetric heat capacity of water phase. Assigning $(\rho C)_{s}$ of the volumetric heat capacity of solid phase and $(\rho C)_{a}$ of the volumetric heat capacity of air phase, the bulk volumetric heat capacity $(\rho C)$ is calculated by

$$
(\rho C)=\varepsilon S(\rho C)_{w}+\varepsilon(1-S)(\rho C)_{a}+(1-\varepsilon)(\rho C)_{s}
$$

The tensor element of $\lambda$ is given by

$$
\lambda_{i j}=\lambda_{e d}+\left(\lambda_{m d}\right)_{i j}=(\rho C) D_{i j}
$$

where $\lambda_{e d}$ and $\lambda_{m d}$ are the bulk thermal conductivity and the mechanical thermal dispersivity; $D_{i j}$ is the hydrodynamic dispersion coefficient. And the dispersion tensor is defined by

$$
\begin{aligned}
& D_{i j}=\alpha_{i j k m}\left|v_{k} \| v_{m}\right| /|v|+\kappa_{e} \\
& \alpha_{i j k m}=\alpha_{T} \delta_{i j} \delta_{k m}+\left(\alpha_{L}-\alpha_{T}\right)\left(\delta_{i k} \delta_{j m}+\delta_{i m} \delta_{j k}\right) / 2
\end{aligned}
$$

where $v$ is the average velocity; $v_{k}$ and $v_{m}$ are the velocity components of two coordinate directions, $k$ and $m$; $\delta_{i j}$ is the Kronecker Delta; $\kappa_{e}$ is the bulk thermal diffusivity; $\alpha_{L}$ is the longitudinal dispersivity; $\alpha_{T}$ is the transverse dispersivity.

\section{References}

[1] Fujinawa, K., Iba, T., Fujihara, Y., \& Watanabe, T., Modeling interaction of fluid and salt in an aquifer/ lagoon system, Ground Water, 47(1), pp. 35-48, 2009.

[2] Fujinawa, K., Theoretical studies on heat transfer in saturated porous media with thermal convection. Trans. Japanese Society of Irrigation, Drainage, and Reclamation Eng., 158, pp. 47-56, 1992.

[3] van Genuchten, M.TH., A closed-form equation for predicting the hydraulic conductivity of unsaturated soils. Soil Sci. Soc. Am. J. 44, pp. 892-898, 1980. 